\title{
Lymphocytes promote albuminuria, but not renal dysfunction or histological damage in a mouse model of diabetic renal injury
}

\author{
A. K. H. Lim • F. Y. Ma • D. J. Nikolic-Paterson • \\ A. R. Kitching $\bullet$ M. C. Thomas $\cdot$ G. H. Tesch
}

Received: 9 November 2009/Accepted: 10 March 2010/Published online: 27 April 2010

(C) Springer-Verlag 2010

\begin{abstract}
Aims/hypothesis Diabetic nephropathy is an inflammatory disease with prominent leucocyte infiltration of the kidneys. While the importance of macrophages in diabetic renal injury has been clearly demonstrated, the role of lymphocytes is still unknown. We therefore examined the development of diabetic renal injury in lymphocyte-deficient mice. Methods Streptozotocin was used to induce diabetes in $\operatorname{Ragl}^{-/-}$mice, which lack mature $\mathrm{T}$ and $\mathrm{B}$ lymphocytes, and in wild-type $\left(\operatorname{Ragl}^{+/+}\right)$controls. The development of renal injury was examined over 20 weeks of diabetes.

Results Both groups developed equivalent diabetes, however only $\mathrm{Ragl}^{+/+}$mice had kidney infiltration with CD4, CD8, CD22 and forkhead box P3-positive cells, as well as glomerular immunoglobulin deposition. At 20 weeks, $\mathrm{Ragl}^{+/+}$mice exhibited renal hypertrophy, increased mesangial and interstitial matrix, kidney macrophage accumulation, tubular injury, progressive albuminuria and a decline in renal function. In comparison, diabetic $\mathrm{Ragl}^{-/-}$
\end{abstract}

Electronic supplementary material The online version of this article (doi:10.1007/s00125-010-1757-1) contains supplementary material,

which is available to authorised users.

A. K. H. Lim • F. Y. Ma • D. J. Nikolic-Paterson •

G. H. Tesch $(\triangle)$

Department of Nephrology, Monash Medical Centre,

246 Clayton Road,

Clayton, VIC 3168, Australia

e-mail: greg.tesch@med.monash.edu.au

A. R. Kitching

Monash University Department of Medicine,

Monash Medical Centre,

Clayton, VIC, Australia

M. C. Thomas

Baker Heart Research Institute,

Prahran, VIC, Australia mice showed similar histological damage, matrix expansion, macrophage accrual and loss of renal function, but were protected from increasing albuminuria. This protection was associated with protection against loss of podocytes and glomerular podocin production, and with reduced glomerular macrophage activation.

Conclusions/interpretation These results show that lymphocytes contribute to the development of diabetic albuminuria, which may partly arise from increasing glomerular macrophage activation and podocyte damage. In contrast, lymphocytes do not appear to promote tubular injury, increased matrix deposition or decline in renal function in a mouse model of type 1 diabetes. Our findings suggest that innate immunity rather than adaptive immune responses are the major inflammatory contributor to the progression of diabetic renal injury.

Keywords Albuminuria - Diabetic nephropathy · Immunoglobulin · Inflammation · Lymphocytes . Macrophage $\cdot$ Mouse $\cdot$ Rag1 deficiency $\cdot$ Renal injury Streptozotocin

$\begin{array}{ll}\text { Abbreviations } \\ \text { FOXP3 } & \text { Forkhead box P3 } \\ \text { gcs } & \text { Glomerular cross-section } \\ \text { MCP-1 } & \text { Monocyte chemoattractant protein 1 } \\ \text { PAS } & \text { Periodic acid-Schiff's } \\ \text { PLP } & \text { Paraformaldehyde-lysine-periodate } \\ \text { SMA } & \text { Smooth muscle actin } \\ \text { WT1 } & \text { Wilm's tumour antigen 1 }\end{array}$

\section{Introduction}

The accumulation of inflammatory cells in renal biopsies of diabetic patients is associated with tissue damage and a 
progressive decline in renal function [1]. In animal models, the use of immunosuppressants, neutralising antibodies and genetic deficiencies has shown that reduction of leucocyte accumulation and activation in diabetic kidneys suppresses the development of renal injury [2]. Most of this research has focused on the contribution of macrophages, which are the major infiltrating immune cell in diabetic kidneys. However, many of these previous studies have used antiinflammatory strategies that also suppress accumulation of lymphocytes in diabetic kidneys, indicating that lymphocytes may also contribute to disease progression.

Lymphocytes may play a role in the development of diabetic nephropathy, despite any clear evidence of antigen involvement. $T$ cells are known to play a significant role in renal injury induced by non-immune insults including ischaemia or toxins (e.g. adriamycin) [3, 4]. Activated $\mathrm{T}$ cells can cause injury directly through cytotoxic effects and indirectly by recruiting and activating macrophages. In addition, kidney autoantigens may develop during chronic diabetic renal injury and, if this occurs, B cells could present these antigens to $T$ cells to promote their activation. Furthermore, diabetic patients have increased levels of serum immunoglobulins, which include antibodies against proteins modified by glycoxidation or lipoxidation $[5,6]$. These circulating antibodies can form immune complexes [6,7], which may deposit in glomeruli and promote activation of complement or macrophages via receptor interactions.

The development of diabetic renal injury has been associated with $\mathrm{T}$ cell activation in the circulation and $\mathrm{T}$ cell accumulation in the kidney. Type 1 diabetic patients with mild proteinuria have higher levels of circulating activated lymphocytes than non-proteinuric patients; these levels decline when patients develop nephrotic-range proteinuria [8]. This suggests that lymphocyte activation may play a role in early diabetic nephropathy. A recent clinical study also established that $\mathrm{T}$ cell infiltration of the juxtaglomerular apparatus is common during the early stages of type 1 diabetes and correlates with an increased filtration surface per glomerulus and a lower albumin excretion rate [9]. This suggests that $\mathrm{T}$ cells in the juxtaglomerular apparatus could delay the onset of albuminuria in type 1 diabetic patients. In addition, rodent models of type 1 and type 2 diabetic nephropathy have demonstrated that CD4+ and CD8+ $\mathrm{T}$ cells accumulate in the glomeruli and interstitium of diabetic kidneys, but on a much smaller scale than macrophages [10-12], suggesting that these cells may interact with macrophages to regulate inflammation and renal injury. In comparison, there is no direct evidence that B cells infiltrate the kidney during diabetes. However, the involvement of $\mathrm{B}$ cells is indicated by studies showing glomerular deposition of immunoglobulin in experimental diabetic nephropathy $[11,13-15]$
Elements of the diabetic milieu can directly or indirectly activate $\mathrm{T}$ cells in diabetic kidneys. CD4+ T cells express the receptor for AGEs and can respond to AGEs by producing IFN- $\gamma$, which could exacerbate inflammation in the diabetic kidney [16]. In addition, hyperglycaemia induces macrophage production of IL-12, which can also stimulate CD4 cell production of IFN- $\gamma$ [17]. In diabetic kidneys of NOD mice, accumulation of CD8+ cells, which also express the receptor for AGE, is associated with increased expression of genes encoding perforin and granzyme B, and with co-localisation in immunostaining for perforin [14]. This suggests that CD8+ cells may exert a cytolytic function in the diabetic kidney. It is also noteworthy that some CD4+ cells in diabetic kidneys could be T-regulatory cells and play a role in suppressing inflammation, although this has yet to be investigated.

It is important to identify the functional role of lymphocytes in diabetic renal injury, as researchers would then be able to determine the relative contribution of innate and adaptive immune components. This would help in the development of anti-inflammatory strategies to treat diabetic nephropathy. Mice deficient in $\operatorname{Ragl}\left(\operatorname{Ragl}^{-/}\right)$do not produce mature $\mathrm{T}$ and $\mathrm{B}$ lymphocytes [18] and can be used to monitor the development of kidney disease in the absence of lymphocytes [19]. In the current study, we used streptozotocin to induce equivalent diabetes in wild-type $\left(\operatorname{Rag} 1^{+/+}\right)$and $\operatorname{Ragl}^{-/-}$mice, and examine the impact of lymphocyte deficiency on the development of type 1 diabetic nephropathy.

\section{Methods}

Animal model Rag1 ${ }^{-/}$mice with a C57BL/6 background and wild-type controls were obtained from the Animal Resource Centre (Perth, WA, Australia) and were bred under pathogen-free conditions at the Monash Medical Centre Animal Facility (Clayton, VIC, Australia). Groups of 8-week-old male $\operatorname{Rag} 1^{-/-}$and wild-type mice $(n=8-10)$ were given intraperitoneal injections of streptozotocin (Sigma, St Louis, MO, USA) at day $0(100 \mathrm{mg} / \mathrm{kg})$ and day $5(125 \mathrm{mg} / \mathrm{kg})$. Using this protocol, both strains were equally susceptible to the development of streptozotocininduced diabetes and displayed equivalent hyperglycaemia. Mice with significant diabetes (blood glucose $>16 \mathrm{mmol} / \mathrm{l}$ at 2 weeks after the first streptozotocin injection) were followed for 20 weeks. Age-matched non-diabetic Rag1 $1^{-/}$ and wild-type mice $(n=7)$ were used as controls. Mice were housed in pathogen-free micro-isolator cages and maintained on a normal diet. Random morning blood glucose (tail vein sample) and body weight were measured weekly and mice with glucose levels $>30 \mathrm{mmol} / 1$ were given 0.5 units of protaphane insulin (Novo Nordisk, Sydney, 
NSW, Australia) subcutaneously three times a week to maintain body weight. Urine was collected at weeks 8,12 , 16 and 20 to assess urine albumin excretion. $\mathrm{HbA}_{1 \mathrm{c}}$ was measured from blood samples at weeks 8 and 20 to confirm that hyperglycaemia remained equivalent in both diabetic groups. Tissues were collected at week 20 and fixed in $4 \%$ (vol./vol.) formalin, $2 \%$ (wt/vol.) paraformaldehydelysine-periodate (PLP) and methyl Carnoy's fixative (60\% methanol, $30 \%$ chloroform, $10 \%$ glacial acetic acid; vol./vol.), or snap-frozen and stored at $-80^{\circ} \mathrm{C}$. All animal experiments were approved by the Monash Medical Centre Animal Ethics Committee.

Biochemistry Urine was collected from mice housed in metabolism cages for $24 \mathrm{~h}$. Whole blood was collected by cardiac puncture in anaesthetised animals and stored as serum or heparinised plasma. ELISA kits were used to determine urine albumin (Bethyl Laboratories, Montgomery, TX, USA), urine monocyte chemoattractant protein 1 (MCP-1), and serum and urine IL-6 (OptEIA; BD Biosciences, San Diego, CA, USA) as per manufacturer's instructions. $\mathrm{HbA}_{1 \mathrm{c}}$, and serum and urine creatinine were measured by HPLC. Creatinine clearance was adjusted to body surface area $\left(\mathrm{ml} \mathrm{min}{ }^{-1} \mathrm{~m}^{-2}\right)$.

Histopathology Staining with periodic acid-Schiff's (PAS) reagent and haematoxylin was performed on $2 \mu \mathrm{m}$ sections of formalin-fixed kidney for structural assessment and morphometric analysis. Glomerular volume and PAS+ mesangial matrix fraction were analysed by computer image analysis (magnification $\times 400$ ) [20], while total cellularity was determined by counting nuclei in 20 hilar glomerular cross sections (gcs) per animal. Tubular injury was assessed by counting injured tubules (dilated, atrophic, necrotic) as a percentage of total tubules in ten cortical fields (magnification $\times 250$ ). All scoring was performed on blinded slides.

Antibodies The primary antibodies used in this study were: rabbit anti-Wilm's tumour antigen 1 (WT1) (Santa Cruz Biotechnology, Santa Cruz, CA, USA); goat anti-collagen IV (Southern Biotechnology, Birmingham, AL, USA); rabbit anti-cleaved caspase 3 (ASP175), rabbit antiphospho-p38 mitogen-activated protein kinase (Thr180/ Tyr182) and rabbit anti-phospho-c-Jun amino-terminal kinase (Thr183/Thy185; Cell Signaling, Beverly, MA, USA); rat anti-mouse Ki-67 (TEC-3; Dako, Carpinteria, CA, USA); rat anti-CD68 and rat anti-CD169 (Serotec, Oxford, UK); rat anti-mouse forkhead box P3 (FOXP3; eBiosciences, San Diego, CA, USA); mouse anti- $\alpha$ tubulin, fluorescein conjugated mouse anti- $\alpha$-smooth muscle actin (SMA) and rabbit anti-podocin (SigmaAldrich, St Louis, MO, USA); biotinylated mouse anti-
CD22.2 (BD Pharmingen, San Diego, CA, USA); and rat anti-CD4 (GK1.5) and anti-CD8 (YTS169) were produced by cell culture of hybridomas obtained from the American Tissue Culture Collection (Manassas, VA, USA).

Immunohistochemistry Immunostaining for WT1, $\alpha$-SMA, cleaved caspase-3 and Ki-67 was performed on $4 \mu \mathrm{m}$ formalin-fixed paraffin sections. Immunostaining for collagen IV was performed on $4 \mu \mathrm{m}$ sections fixed in methyl Carnoy's solution. Immunostaining for CD4, CD8, CD68 and CD169 was performed on $5 \mu \mathrm{m}$ PLP-fixed cryostat sections, while immunostaining for FOXP3 and CD22 was performed on $6 \mu \mathrm{m}$ snap-frozen sections. For retrieval of antigens in formalin-fixed sections (except $\alpha$-SMA), slides were heated in a pressure cooker (high setting $20 \mathrm{~min}$, full pressure $5 \mathrm{~min}$ ) in a $10 \mathrm{mmol} / \mathrm{l}$ sodium citrate buffer $(\mathrm{pH} 6)$. Endogenous peroxidise was quenched by immersing slides in 3\% (vol./ vol.) $\mathrm{H}_{2} \mathrm{O}_{2} / \mathrm{PBS}$ (formalin-fixed sections) or $0.5 \%$ (vol./vol.) $\mathrm{H}_{2} \mathrm{O}_{2} /$ methanol (PLP and snap-frozen sections). Antigens were labelled by overnight incubation with primary antibody, followed by biotinylated secondary antibodies (Vector Laboratories, Burlingame, CA, USA). Detection was done using a standard peroxidase-ABC system (Vector) and development with 3,3-diaminobenzidine (Sigma). For detection of FITC-conjugated anti- $\alpha$-SMA monoclonal antibody, sections were incubated with peroxidase-conjugated sheep anti-fluorescein IgG (Roche Biochemicals, Mannheim, Germany) prior to development with 3,3-diaminobenzidine. For FOXP3 and CD22 staining, frozen sections were fixed in icecold acetone for $10 \mathrm{~min}$ and quenched prior to incubation with primary antibody. Normal rabbit and goat serum or isotypedmatched irrelevant IgGs were used as negative controls.

Immunofluorescence for mouse $\operatorname{Ig} G$ and podocin For detection of $\mathrm{IgG}$, frozen sections $(6 \mu \mathrm{m})$ were fixed in ethanol at $4^{\circ} \mathrm{C}$ for $10 \mathrm{~min}$. After blocking with $10 \%$ (vol./ vol.) sheep serum, sections were incubated with FITCconjugated sheep anti-mouse IgG Fab fragments (Silenus, Melbourne, VIC, Australia) at 1:50 dilution for $30 \mathrm{~min}$. For detection of podocin, frozen sections $(6 \mu \mathrm{m})$ were fixed in acetone on ice for $20 \mathrm{~min}$. Sections were then blocked with $10 \%$ (vol./vol.) normal swine serum and incubated overnight with 1:1000 dilution of rabbit anti-podocin (Sigma) in $1 \%$ (wt/vol.) BSA at $4^{\circ} \mathrm{C}$. The next day sections were incubated with biotinylated swine anti-rabbit IgG (1:500; Dako, Glostrup, Denmark) for $1 \mathrm{~h}$ and then with streptavidinFITC (1:100; Zymed, San Francisco, CA, USA) for $30 \mathrm{~min}$. After immunofluorescence labelling, sections were mounted in anti-fade media containing 5\% (wt/vol.) 1,4-diazabicyclo $[2,2,2$,$] octane (Sigma) and examined with a fluorescence$ microscope (Leica, Wetzlar, Germany). The glomerular area expressing podocin was assessed in 20 glomeruli/section using image analysis. 
Quantification of immunohistochemistry Immunostained cells were counted as cells $/ \mathrm{gcs}$ or cells $/ \mathrm{mm}^{2}$ in the interstitium of the renal cortex in each animal. WT1+ podocytes were counted in 25 hilar ges. CD4+, CD8+, CD68+, CD169+ and $\mathrm{Ki}-67+$ cells were counted in 25 hilar ges and 50 cortical fields (magnification $\times 400$ ). Cleaved caspase- $3+$ apoptotic cells, FOXP3 + regulatory $\mathrm{T}$ cells and $\mathrm{CD} 22+\mathrm{B}$ cells were counted in $50 \mathrm{gcs}$ and the entire kidney cortex. $\alpha$-SMA+ myofibroblast accumulation was assessed by computer image analysis of the percentage area stained in ten cortical fields (magnification $\times 250$ ). Glomerular collagen IV accumulation was assessed as the percentage of area stained in 25 hilar gcs, while tubulointerstitial collagen IV was assessed by measuring the area stained in ten cortical fields (magnification $\times 250$ ), excluding glomeruli and blood vessels.

Real-time PCR Total RNA was extracted from wholekidney samples using a reagent (RiboPure; Ambion, Austin, TX, USA) and reverse-transcribed using a kit (Superscript First-Strand Synthesis; Invitrogen, Carlsbad, CA, USA) with random primers. Real-time PCR was performed (Rotor-Gene 3000 system; Corbett Research, Sydney, NSW, Australia) with thermal cycling conditions of $37^{\circ} \mathrm{C}$ for $10 \mathrm{~min}$ and $95^{\circ} \mathrm{C}$ for $5 \mathrm{~min}$, followed by 50 cycles at $95^{\circ} \mathrm{C}$ for $15 \mathrm{~s}, 60^{\circ} \mathrm{C}$ for $20 \mathrm{~s}$ and $68^{\circ} \mathrm{C}$ for $20 \mathrm{~s}$. The primer pairs and FAM-labelled MGB probes used are shown in the Electronic supplementary material (ESM) Table 1. The relative amount of mRNA was calculated using comparative $\mathrm{Ct}(\Delta \Delta \mathrm{Ct})$ method. All specific amplicons were normalised against $18 \mathrm{~S}$ rRNA, which was amplified in the same reaction as an internal control using commercial assay reagents (Applied Biosystems, Scoresby, VIC, Australia). Each of the primer/probe sets was pre- tested and determined to have equivalent PCR amplification efficiencies.

Statistical analysis Statistical differences between two groups were analysed by the unpaired Student's $t$ test. Those between multiple groups were analysed by one-way ANOVA with Tukey's multiple comparison post-test. Correlations were performed using Pearson's correlation coefficient. Data were recorded as mean $\pm \mathrm{SD}$, with $p<0.05$ considered to denote significance. All analyses were performed using GraphPad Prism 5.0 (GraphPad, San Diego, CA, USA).

\section{Results}

Development of diabetes in $\mathrm{Ragl}^{-/}$mice Preliminary studies (data not shown) led to our development of a streptozotocin-model which induced equivalent diabetes in wild-type and $\mathrm{Ragl}^{-/}$mice. Using this protocol, we found that both groups of diabetic mice showed a similar profile in body weight and progression of hyperglycaemia over the 20 week examination period (Fig. 1a, b). Both diabetic groups also demonstrated an equivalent increase in $\mathrm{HbA}_{1 \mathrm{c}}$ levels at weeks 8 and 20 (Fig. 1c).

Lymphocyte accumulation in diabetic kidneys Immunostaining identified a two- to threefold increase in glomerular and interstitial CD4+ and CD8+ T cells in diabetic wildtype compared with non-diabetic wild-type kidneys (Fig. 2a, b, d, e). There was also a fivefold increase in interstitial FOXP3+ regulatory $\mathrm{T}$ cells in diabetic compared with non-diabetic wild-type mice (Fig. 2f), which accounted for approximately $15 \%$ of the CD4+ infiltrate;
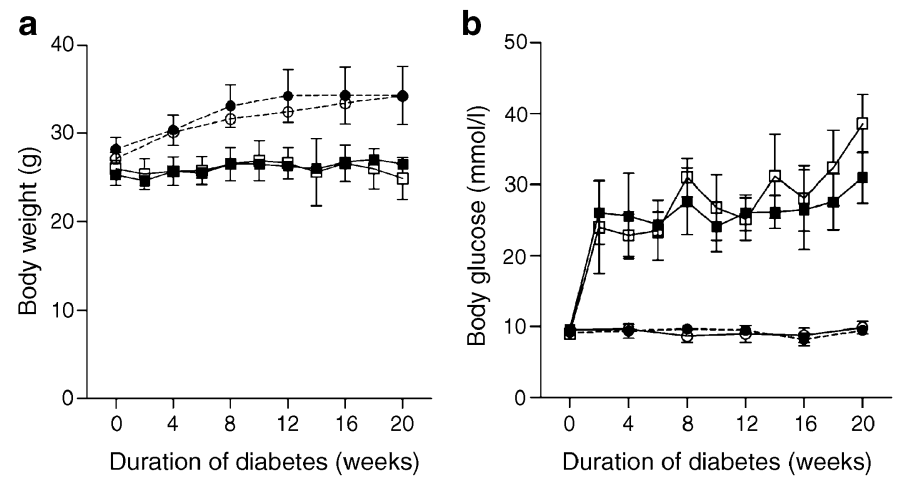

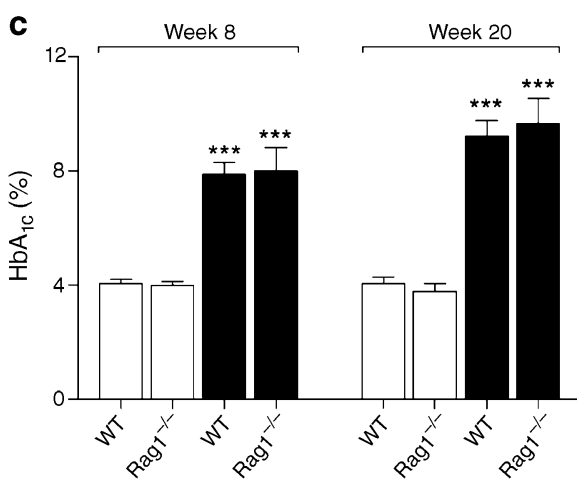

Fig. 1 Lymphocytes did not affect the development of streptozotocininduced diabetes in the experimental mice. Following treatment with streptozotocin, $\operatorname{Ragl}^{-1-}$ and wild-type C57BL/6 mice became diabetic and demonstrated similar profiles of (a) body weight and (b) blood glucose over a 20 -week period (black circles, non-diabetic wild-type mice; white circles, non-diabetic Ragl $1^{-/}$mice; black squares, diabetic wild-type mice; white squares, diabetic $\operatorname{Rag} 1^{-/}$mice). c Assessment of $\mathrm{HbA}_{1 \mathrm{c}}$ confirmed that diabetic $\mathrm{Ragl}^{-/-}$and wild-type mice had equivalent hyperglycaemia at weeks 8 and 20 (white bars, non-diabetic; black bars, diabetic). Data are means $\pm \mathrm{SD}, n=7-10$; $* * * p<0.001$ vs non-diabetic control 


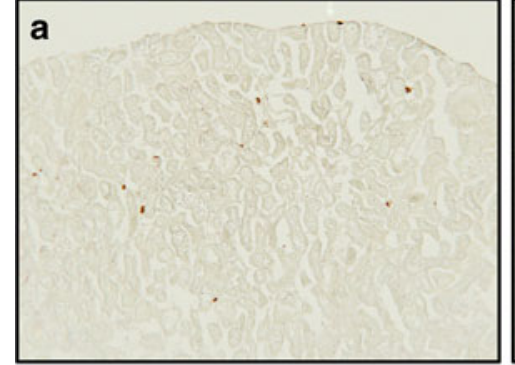

d

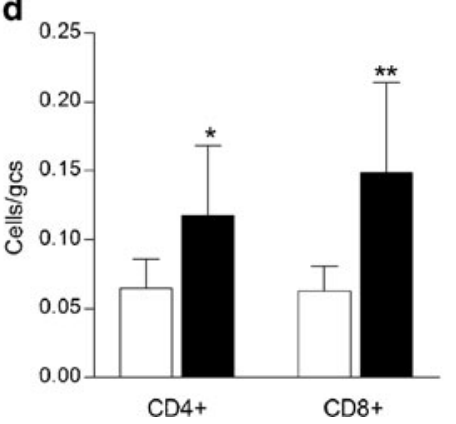

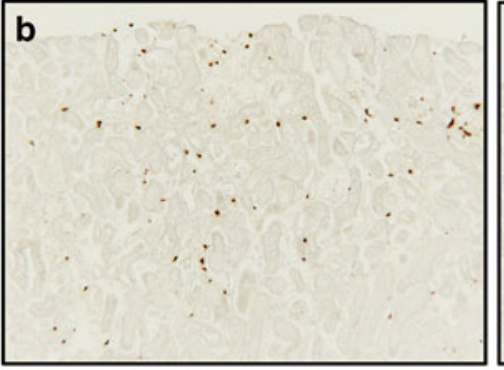

e

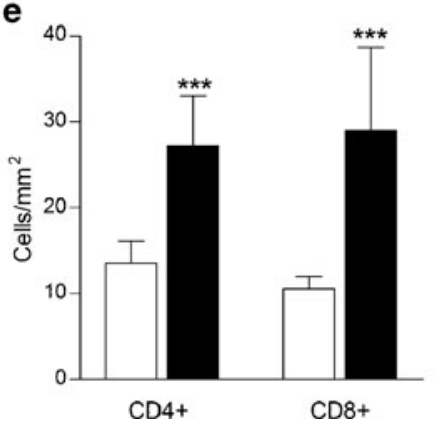

c

f

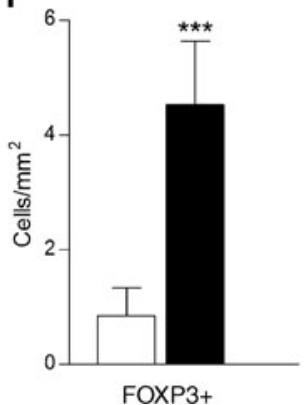

Fig. $2 \mathrm{~T}$ cell accumulation in the kidney of diabetic mice. Representative immunostaining of lymphocytes demonstrated a few CD8+ T cells in the cortex of (a) a normal mouse kidney, but these numbers were increased approximately threefold in (b) the kidney cortex of a wild-type diabetic mouse. As expected, no CD8+ lymphocytes were detected in (c) the diabetic kidney of a $\mathrm{Ragl}^{-/-}$ mouse. Magnification $(\mathbf{a}-\mathbf{c}) \times 100$. The total numbers of $\mathrm{CD} 4+$ and CD8+ in (d) glomeruli and (e) the interstitium of the kidney cortex

however, no FOXP3+ cells were detected in wild-type glomeruli. In comparison, $\mathrm{CD} 22+\mathrm{B}$ cells were rarely detected by immunostaining, only accounting for about $1 \%$ of total lymphocytes within the wild-type kidney. A small but significant increase in glomerular B cells was observed in diabetic compared with non-diabetic wild-type mice $(6.1 \pm 2.5$ vs $2.8 \pm 2.1$ cells $/ 30$ gcs, $p=0.03)$. However, interstitial B cells were not significantly increased in diabetic wild-type kidneys $\left(0.46 \pm 0.26\right.$ vs $0.26 \pm 0.12$ cells $/ \mathrm{mm}^{2}$, $p=0.21)$. As expected, no T- or B-lymphocytes were identified in the kidneys of $\operatorname{Rag} 1^{-/-}$mice (Fig. 2c, B cell data not shown).

Lymphocyte deficiency reduces albuminuria and prevents some glomerular changes in diabetic kidneys Ragl ${ }^{-1-}$ mice had a higher urine AER than non-diabetic wild-type controls, although this just failed to reach statistical significance $(52.9 \pm 7.0$ vs $30.7 \pm 5.7 \mu \mathrm{g} / 24 \mathrm{~h}, p=0.05)$. As we found no differences in any of the glomerular and tubular variables examined in the non-diabetic strains, the cause of this divergence is unclear. To compensate for this baseline difference, we compared urine AER in diabetic mice in terms of the fold-increase in each strain relative to their non-diabetic levels (i.e. baseline=1). Accordingly, diabetic wild-type mice showed a progressive rise in urine AER after week 8, which was increased more than sixfold were assessed at week 20 in diabetic (black bars) wild-type mice and their non-diabetic (white bars) controls. Immunostaining also revealed a marked increase in (f) interstitial FOXP3 $+\mathrm{T}$ cells in the kidney cortex of diabetic compared with non-diabetic wild-type mice. CD4+ and FOXP3 + T cells were absent in $\mathrm{Ragl}^{-1-}$ mice (not shown). Data (d-f) are means $\pm \mathrm{SD}, n=7-10 ;{ }^{*} p<0.05, * * p<0.01, * * * p<0.001$ vs non-diabetic control

at week 20 compared with non-diabetic wild-type mice (Fig. 3). In contrast, urine AER in $R A G 1^{-/-}$diabetic mice was increased twofold at 8 weeks, but did not progress between weeks 8 and 20 (Fig. 3). The protection against increasing albuminuria seen in $\operatorname{Rag1^{-/}}$ mice was also validated by measuring the urine albumin/creatinine ratio at week 20 (Table 1). Examination of WT1+ immunostaining demonstrated that podocyte numbers and glomerular podocin levels were reduced in diabetic wild-type kidneys at week 20; however, diabetic $\operatorname{Rag} 1^{-/-}$mice were partially protected from loss of podocytes and fully protected from loss of podocin production (Table 1). In this model, podocyte numbers showed a strong correlation with urine AER $(r=-0.72, p<0.001)$.

Immunofluorescence analysis identified moderate $\operatorname{IgG}$ deposition in the glomeruli of diabetic wild-type mice, which was completely absent in $\operatorname{Ragl^{-/}}$ mice (Fig. 4). The numbers of total glomerular CD68+ macrophages were increased two- to threefold in diabetic compared with nondiabetic wild-type mice, a development not significantly altered by Ragl knockout (Table 1). The number of CD169+-activated macrophages was increased three- to fourfold in the glomeruli of diabetic compared with nondiabetic wild-type mice; however, these numbers were markedly reduced in $\mathrm{Ragl}^{-/-}$mice (Table 1). The degree of urine AER in diabetic mice also correlated with glomerular 


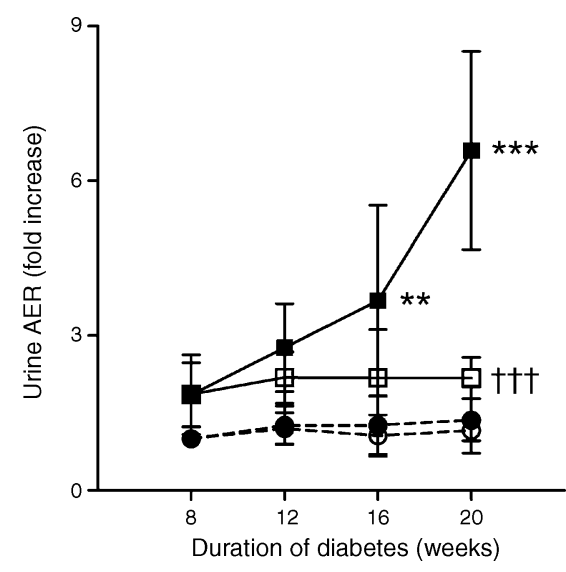

Fig. 3 Lymphocyte deficiency suppresses albuminuria in diabetic mice. Diabetic mice showed an early twofold increase in urine AER at 8 weeks compared with control mice. Despite a progressive increase in urine AER in diabetic wild-type mice from week 8 to week 20, urine AER in diabetic $R a g 1^{-1-}$ mice remained static, indicating that lymphocyte deficiency abrogated progressive albuminuria in diabetic nephropathy. Data are means $\pm \mathrm{SD}, n=7-10 ; * * p<0.01$ and $* * * p<$ 0.001 vs non-diabetic control; ${ }^{\dagger} p<0.001$ vs diabetic wild-type. Black circles, non-diabetic wild-type mice; white circles, non-diabetic $\mathrm{Ragl}^{-/}$mice; black squares, diabetic wild-type mice; white squares, diabetic $\operatorname{Ragl}^{-1}$ mice

macrophage activation $(r=0.50, p=0.04)$, but there were insufficient data pairs to determine correlations with lymphocyte counts. Despite these positive findings, lymphocyte deficiency had no effect on several other histological changes seen in diabetic glomeruli, including increased glomerular cellularity, hypertrophy, proliferation, apoptosis and matrix deposition (Table 1).

Lymphocyte deficiency does not protect diabetic kidneys from hypertrophy, tubulointerstitial injury or renal dysfunction Diabetic wild-type and $\operatorname{Rag} 1^{-/}$mice both exhibited a $40 \%$ increase in the kidney/body weight ratio compared with non-diabetic mice, indicating similar renal hypertrophy (Table 2). Diabetic wild-type mice also demonstrated increased tubular atrophy, apoptosis and proliferation, which were unaffected by Ragl knockout (Fig. 5a-c, Table 2). Equal levels of interstitial fibrosis were observed in diabetic wild-type and $\mathrm{Ragl}^{-/}$mice, including increased myofibroblast accumulation ( $\alpha$-SMA+cells) and tubulointerstitial deposition of collagen IV (Fig. 5d-f, Table 2). In addition, significant tubulointerstitial damage was indicated by increased gene expression of Kim-1(also known as Havcr1), $F n 1$ (also known fibronectin1) and Pai-1 (also known as Serpine1) in diabetic compared with non-diabetic wild-type mice, a development unchanged by Ragl knockout (Fig. $5 \mathrm{~g}-\mathrm{i}$ ). The development of histological damage in diabetic wild-type kidneys at week 20 was associated with a $35 \%$ decline in creatinine clearance. A similar value was observed in diabetic $\operatorname{Ragl}^{-/}$mice, demonstrating equivalent renal dysfunction (Fig. 6).

Lymphocyte deficiency does not reduce interstitial inflammation in diabetic kidneys After 20 weeks of diabetes, the total number of interstitial macrophages (CD68+ cells) was increased three- to fourfold and interstitial accumulation of the CD169+-activated macrophage subset was increased 17-fold in diabetic compared with nondiabetic wild-type kidneys. Equivalent increases were also found in diabetic Ragl $1^{-1-}$ mice (Fig. 7a-c, Table 2). Urine analysis revealed that excretion of IL- 6 and MCP-1 were increased about threefold in diabetic compared with nondiabetic wild-type mice and were unchanged by Rag1 knockout (Fig. 7d, e). Similarly, expression of Ccl2 was increased tenfold in diabetic compared with non-diabetic wild-type kidneys and was unaffected by the absence of
Table 1 Assessment of glomerular injury
Data are means $\pm \mathrm{SD}, n=7-10$

${ }^{\mathrm{a}} p<0.05,{ }^{\mathrm{b}} p<0.01,{ }^{\mathrm{c}} p<0.001 \mathrm{vs}$

wild-type control mice; ${ }^{\mathrm{d}} p<0.05$,

${ }^{\mathrm{e}} p<0.01,{ }^{\mathrm{f}} p<0.001 \mathrm{vs}$

wild-type diabetic mice

ACR, albumin:creatinine ratio; $\mathrm{M} \Phi$, macrophages

\begin{tabular}{|c|c|c|c|c|}
\hline \multirow[t]{2}{*}{ Variable } & \multicolumn{2}{|l|}{ Control } & \multicolumn{2}{|l|}{ Diabetic } \\
\hline & Wild-type & $\operatorname{Rag} 1^{-1-}$ & Wild-type & $\operatorname{Rag} 1^{-1-}$ \\
\hline Urine ACR $(\mu \mathrm{g} / \mu \mathrm{mol})$ & $7.9 \pm 2.4$ & $15.0 \pm 2.1^{\mathrm{c}}$ & $60.8 \pm 17.1^{\mathrm{c}}$ & $34.3 \pm 11.2^{\mathrm{b}, \mathrm{f}}$ \\
\hline \multicolumn{5}{|l|}{ Glomerular } \\
\hline Volume $\left(\mu \mathrm{m}^{3} \times 10^{4}\right)$ & $18.9 \pm 1.9$ & $19.0 \pm 1.4$ & $21.1 \pm 2.8$ & $23.7 \pm 3.6^{\mathrm{b}}$ \\
\hline Total cellularity (cells/gcs) & $29.9 \pm 1.8$ & $29.2 \pm 1.6$ & $37.8 \pm 3.0^{\mathrm{c}}$ & $39.1 \pm 2.3^{\mathrm{c}}$ \\
\hline Podocytes (cells/gcs) & $13.6 \pm 0.4$ & $13.5 \pm 0.4$ & $10.7 \pm 0.4^{\mathrm{c}}$ & $11.4 \pm 0.5^{\mathrm{c}, \mathrm{e}}$ \\
\hline Podocin (\%) & $19.0 \pm 1.5$ & $19.4 \pm 1.9$ & $14.1 \pm 2.7^{\mathrm{c}}$ & $18.9 \pm 2.1^{\mathrm{f}}$ \\
\hline Proliferation (cells/gcs) & $0.29 \pm 0.06$ & $0.29 \pm 0.07$ & $0.41 \pm 0.15^{\mathrm{a}}$ & $0.38 \pm 0.15^{\mathrm{a}}$ \\
\hline Apoptosis (cells/50 gcs) & $2.00 \pm 1.00$ & $1.86 \pm 0.69$ & $6.40 \pm 2.07^{\mathrm{c}}$ & $4.50 \pm 2.73^{\mathrm{c}}$ \\
\hline PAS + matrix $(\%)$ & $27.7 \pm 1.6$ & $27.1 \pm 1.5$ & $37.2 \pm 1.7^{\mathrm{c}}$ & $38.1 \pm 1.8^{\mathrm{c}}$ \\
\hline Collagen IV (\%) & $21.9 \pm 3.2$ & $21.8 \pm 1.4$ & $30.9 \pm 2.5^{\mathrm{c}}$ & $28.4 \pm 2.5^{\mathrm{c}}$ \\
\hline \multicolumn{5}{|l|}{ Macrophages } \\
\hline CD68+ M $\Phi$ (cells/gcs) & $0.74 \pm 0.19$ & $0.71 \pm 0.21$ & $2.10 \pm 0.61^{\mathrm{c}}$ & $1.50 \pm 0.53^{\mathrm{a}}$ \\
\hline CD169+ M $\Phi$ (cells/gcs) & $0.06 \pm 0.06$ & $0.02 \pm 0.02$ & $0.29 \pm 0.23^{\mathrm{a}}$ & $0.07 \pm 0.06^{\mathrm{a}, \mathrm{d}}$ \\
\hline
\end{tabular}



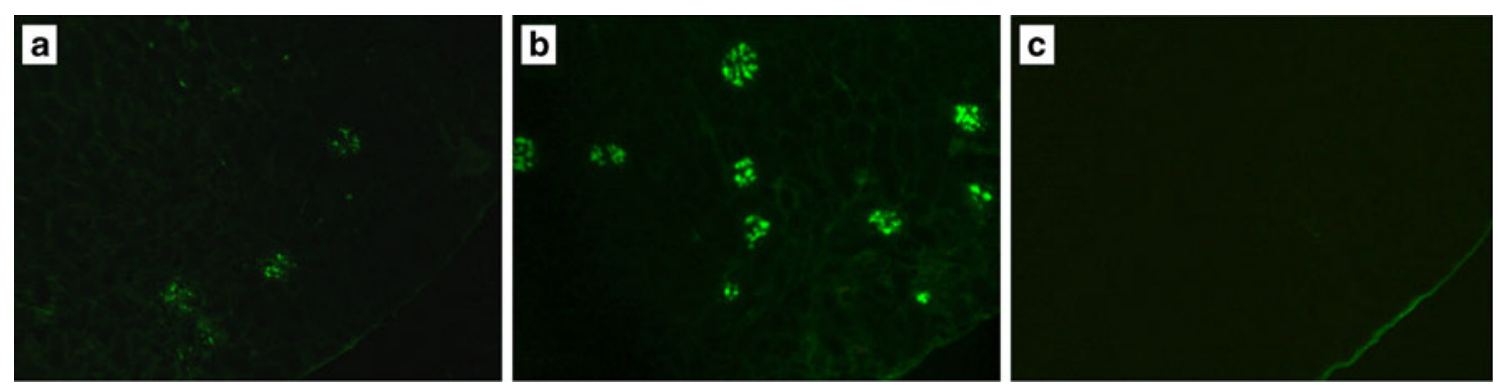

Fig. 4 Lymphocyte deficiency prevents glomerular IgG deposition in diabetic mice. a A faint fluorescence signal for IgG was detected in the glomeruli of non-diabetic control mice. b The glomeruli of diabetic wild-type mice had moderate fluorescence signal intensity,

lymphocytes (Fig. 7f). In contrast, kidney gene expression of the T cell-related cytokines $I l 12$ (also known as $I l 12 b$ ), Ifn- $\gamma$ (also known as Ifng) and Ill0 was not elevated in diabetic compared with non-diabetic wild-type mice and did not change with Ragl knockout (data not shown). In addition, serum levels of IL-6 were also unchanged in diabetic and non-diabetic mouse strains (data not shown).

\section{Discussion}

Our investigation showed that the development of early diabetic renal injury is associated with significant lymphocyte infiltration. We identified an increase in glomerular and interstitial CD4+ and CD8+ T cells in our mouse model of type 1 diabetes, which is consistent with other rodent models of diabetes [10-12]. We also found that FOXP3+ Tregulatory cells accumulate in the interstitium of diabetic kidneys. In comparison, B cells were rarely detected in any indicating increased deposition of IgG. c A complete absence of fluorescence signal was noted in $\mathrm{Ragl}^{-/}$kidneys, consistent with absence of IgG within glomeruli. Magnification $\times 100$

part of the diabetic kidney, but $\operatorname{IgG}$ was deposited in the glomeruli of diabetic mice. A genetic deficiency (knockout) of Ragl resulted in mice (and kidneys) devoid of these lymphocytes, but did not alter the development of diabetes in our model, which enabled us to determine the impact of the total lymphocyte infiltrate on diabetic renal injury. However, this study did not examine whether particular subsets of lymphocytes, whose activity may be regulated by interactions with other types of lymphocytes, played discrete roles. In addition, we should also point out that this study did not use the common multiple low-dose model of streptozocin induction of diabetes [21], because $\mathrm{Ragl}^{-/}$ mice were resistant to the pancreatic injury induced by this protocol. Instead, we used a previously described two-dose model of streptozotocin-induced diabetes, which does not cause acute kidney damage [22].

Lymphocyte deficiency had a selective effect on glomerular inflammation. Kidney macrophage numbers, which were approximately tenfold greater than lymphocytes in diabetic
Table 2 Assessment of tubulointerstitial injury
Data are means $\pm \mathrm{SD}, n=7-10$

${ }^{\mathrm{a}} p<0.05,{ }^{\mathrm{b}} p<0.01,{ }^{\mathrm{c}} p<0.001$ vs wild-type control mice

BW, body weight; KW, kidney weight; $\mathrm{M} \Phi$, macrophages

\begin{tabular}{|c|c|c|c|c|}
\hline \multirow[t]{2}{*}{ Variables } & \multicolumn{2}{|l|}{ Control } & \multicolumn{2}{|l|}{ Diabetic } \\
\hline & Wild-type & $\operatorname{Rag} 1^{-1-}$ & Wild-type & $\operatorname{Rag1} 1^{-1-}$ \\
\hline \multicolumn{5}{|l|}{ Kidney hypertrophy } \\
\hline KW:BW (\%) & $1.21 \pm 0.24$ & $1.21 \pm 0.25$ & $1.65 \pm 0.10^{\mathrm{c}}$ & $1.73 \pm 0.24^{\mathrm{c}}$ \\
\hline \multicolumn{5}{|l|}{ Tubular injury } \\
\hline Atrophy (\%) & $0.28 \pm 0.11$ & $0.35 \pm 0.19$ & $5.63 \pm 2.50^{\mathrm{c}}$ & $7.89 \pm 3.10^{\mathrm{c}}$ \\
\hline Apoptosis (cells $/ \mathrm{mm}^{2}$ ) & $0.25 \pm 0.07$ & $0.35 \pm 0.12$ & $1.89 \pm 0.58^{\mathrm{c}}$ & $1.82 \pm 0.76^{\mathrm{c}}$ \\
\hline Proliferation (cells $/ \mathrm{mm}^{2}$ ) & $18.7 \pm 3.6$ & $22.9 \pm 5.1$ & $51.7 \pm 10.8^{\mathrm{c}}$ & $58.0 \pm 19.0^{c}$ \\
\hline \multicolumn{5}{|l|}{ Interstitial injury } \\
\hline Collagen IV (\%) & $13.6 \pm 1.3$ & $13.3 \pm 1.2$ & $20.6 \pm 1.9^{c}$ & $21.6 \pm 1.6^{\mathrm{c}}$ \\
\hline$\alpha$-SMA (\%) & $0.23 \pm 0.10$ & $0.29 \pm 0.20$ & $3.23 \pm 0.79^{\mathrm{c}}$ & $4.08 \pm 1.66^{\mathrm{c}}$ \\
\hline Apoptosis (cells $/ \mathrm{mm}^{2}$ ) & $0.57 \pm 0.13$ & $0.63 \pm 0.18$ & $1.58 \pm 0.63^{\mathrm{c}}$ & $1.41 \pm 0.33^{\mathrm{c}}$ \\
\hline Cell proliferation $(\%)$ & $20.9 \pm 2.2$ & $18.2 \pm 4.8$ & $37.5 \pm 15.9^{\mathrm{b}}$ & $35.1 \pm 11.0^{\mathrm{a}}$ \\
\hline \multicolumn{5}{|l|}{ Macrophages } \\
\hline $\mathrm{CD} 68+\mathrm{M} \Phi\left(\right.$ cells $\left./ \mathrm{mm}^{2}\right)$ & $123 \pm 27$ & $114 \pm 23$ & $409 \pm 84^{c}$ & $429 \pm 62^{c}$ \\
\hline $\mathrm{CD} 169+\mathrm{M} \Phi\left(\right.$ cells $\left./ \mathrm{mm}^{2}\right)$ & $17 \pm 3$ & $20 \pm 2$ & $306 \pm 53^{\mathrm{c}}$ & $320 \pm 32^{\mathrm{c}}$ \\
\hline
\end{tabular}



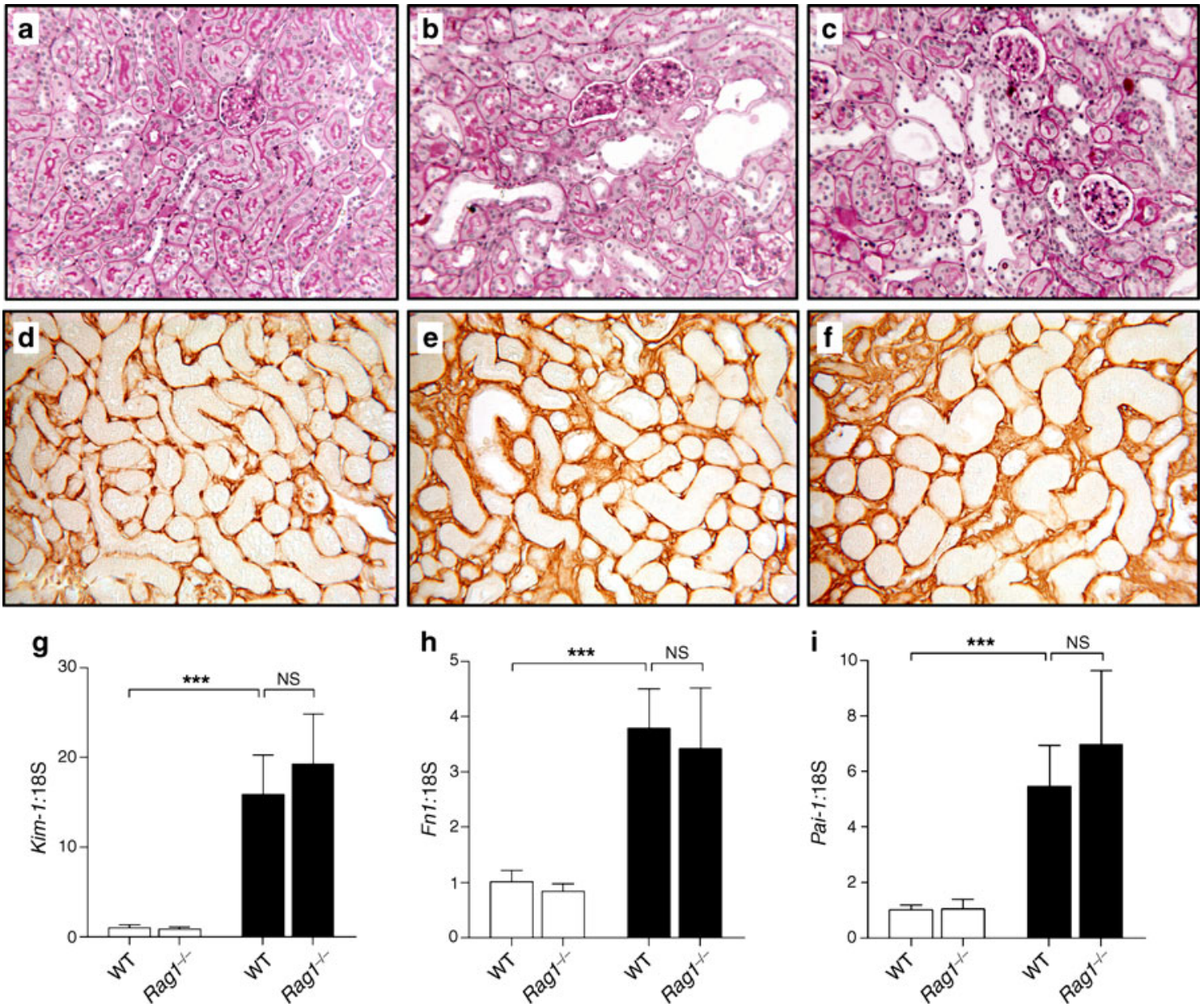

Fig. 5 Lymphocytes do not promote the progression of tubulointerstitial injury in diabetic mice. Compared with control mice (a, d), the kidneys of diabetic wild-type $(\mathbf{b}, \mathbf{e})$ and $\operatorname{Ragl}^{-/}(\mathbf{c}, \mathbf{f})$ mice demonstrated significant tubular atrophy in PAS staining $(\mathbf{a}-\mathbf{c})$ and interstitial fibrosis (collagen IV) $(\mathbf{d}-\mathbf{f})$, which were unaffected by lymphocyte deficiency; magnification $\times 250$. When compared with

non-diabetic mice (white bars), diabetic mice (black bars) showed a (g) 15-fold increase in Kim-1 mRNA, (h) threefold increase in Fn1 mRNA and (i) fivefold increase in Pai-1 mRNA. The gene transcript levels of these markers of tubulointerstitial injury were not reduced in lymphocyte-deficient $\operatorname{Ragl}^{-/-}$mice. Data are means $\pm \mathrm{SD}, n=6-10$; $* * * p<0.001$

wild-type mice, were unchanged in $\mathrm{Ragl}^{-/}$diabetic mice. In addition, expression of $\mathrm{Ccl} 2$ and urine excretion of MCP-1 were equally increased in wild-type and $\mathrm{Ragl}^{-/}$diabetic kidneys, indicating that the major mechanism for kidney macrophage recruitment had not been affected by the absence of lymphocytes. Urine levels of IL-6 were also increased by similar amounts in both diabetic strains, suggesting that the kidney inflammatory response was comparable. Surprisingly, Ragl knockout reduced the number of CD169+-activated macrophages to near normal levels in diabetic glomeruli, but not in the interstitium. This suggests that lymphocytes help promote glomerular macrophage activation during diabetes. However, our examination of wild-type and $\mathrm{Ragl}^{-1}$ diabetic kidneys found no changes in expression of Ifn- $\gamma$, which is known to promote macrophage activity, suggesting that $\mathrm{T}$ cells may have little involvement in regulating macrophage activity in diabetic kidneys.
Analysis of diabetic $\mathrm{Ragl}^{-/}$mice showed that lymphocytes promoted the progression of albuminuria between weeks 8 and 20 of diabetes. The loss of podocytes and glomerular podocin production at week 20 correlated with the development of albuminuria and was significantly inhibited in the absence of lymphocytes, suggesting that lymphocytes play a role in podocyte injury that leads to greater urinary albumin excretion during diabetes. The mechanisms by which lymphocytes induce podocyte injury during diabetes are unclear, but may involve activation of glomerular macrophages, which was markedly reduced in diabetic Rag1 $1^{-/}$mice. T cells found in glomeruli (CD4+, $\mathrm{CD} 8+$ ) may stimulate neighbouring macrophages to become activated by increasing the local levels of activating cytokines. $\mathrm{T}$ cell secretion of proinflammatory cytokines can activate glomerular macrophages directly and also indirectly by stimulating mesangial cell production of colony 


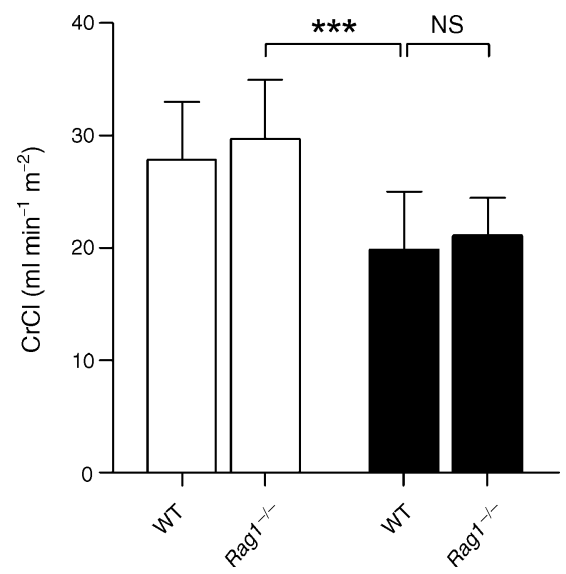

Fig. 6 Lymphocyte deficiency does not protect diabetic mice from renal dysfunction. At 20 weeks, both wild-type and $R a g 1^{-/-}$diabetic mice (black bars) had suffered a $35 \%$ decline in creatinine clearance $(\mathrm{CrCl})$ compared with non-diabetic controls (white bars). Data are means \pm SD, $n=7-10 ; * * * p<0.001$

stimulating factor-1 and MCP-1 [23]. Another possibility is that glomerular macrophages are stimulated by the glomerular deposition of $\mathrm{IgG}$, which is increased during diabetes and was absent in $R a g 1^{-/}$mice. Macrophages possess receptors for the $\mathrm{Fc}$ component of IgG and for $\mathrm{C} 3$, which can both activate macrophages [24, 25]. Increased levels of circulating antibodies to proteins modified by diabetes may form immune complexes, which deposit in glomeruli and potentially activate complement. Circulating immune complex levels have been associated with the development of albuminuria and proliferative retinopathy in diabetic patients suggesting that they could promote tissue injury $[6,7,26]$. However, the presence of glomerular Ig and C3 in patient biopsies cannot be clearly attributed to diabetes and is more commonly considered to be a form of immune complex disease co-existing with diabetic nephropathy [27, 28]. More convincing evidence is seen in experimental animal models, where glomerular deposition of Ig and C3 is due to diabetes alone and correlates with renal injury [11, 13-15]. Our findings in $\operatorname{Rag1^{-/}}$ mice support this concept by demonstrating that glomerular Ig deposition is a complication of diabetes that may play a role in the evolution of diabetic albuminuria.

Another consideration is that lymphocytes may also promote diabetic albuminuria by enhancing tubular hypertrophy and injury. Tubular hypertrophy is known to stimulate glomerular blood flow through a tubular glomerular feedback mechanism [29]. Proximal tubules can also endocytose and degrade some of the albumin filtered by glomeruli, a process possibly reduced by tubular injury [30]. However, in the current study, we found that diabetic
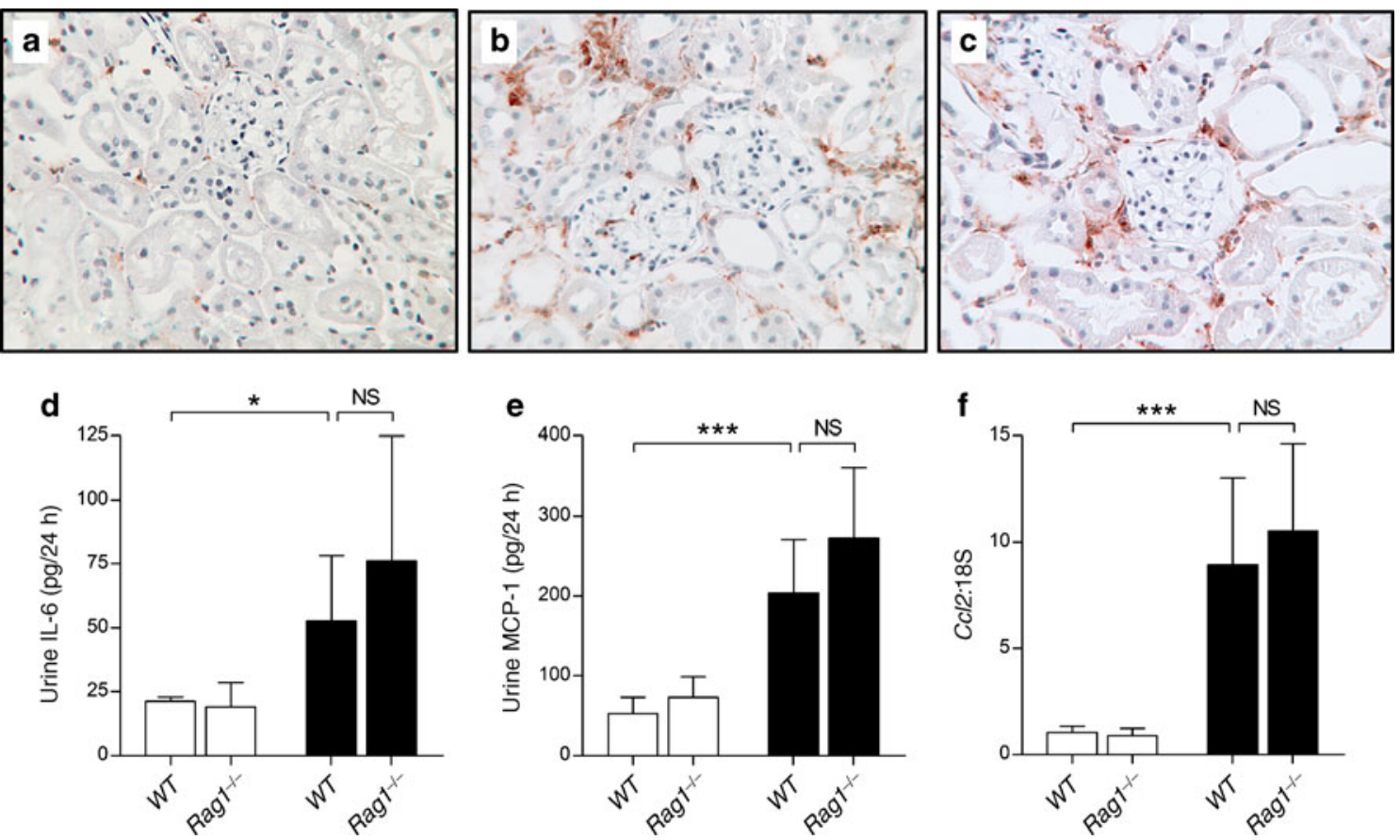

Fig. 7 Lymphocyte deficiency does not reduce tubulointerstitial inflammation in diabetic mice. Macrophages (CD68+ cells, brown) were rarely observed in the cortex of (a) a non-diabetic wild-type mouse kidney, but were increased to a similar degree in (b) a diabetic wild-type mouse kidney and (c) a diabetic $\operatorname{Ragl}^{-/-}$mouse kidney. Sections were counterstained with haematoxylin, magnification $\times 400$. d Urinary excretion of the inflammatory cytokine, IL-6 was increased

threefold in diabetic mice (black bars) compared with non-diabetic (white bars) mice. e Urinary excretion of MCP-1 was increased in diabetic mice, corresponding to (f) upregulated transcription of $\mathrm{Ccl} 2$ in the kidney. The increased urinary excretion of IL-6 and MCP-1, and increased kidney expression of $\mathrm{Ccl} 2$ were not dependent on lymphocytes. Data (d-f) are means $\pm \mathrm{SD}, n=7-10 ; * p<0.05$ and $* * * p<0.001$ vs non-diabetic control 
$\operatorname{Ragl}^{-/-}$were not protected from renal hypertrophy, tubular damage (atrophy, apoptosis, proliferation) or expression of Kim-1, a sensitive marker of tubular injury. These findings suggest that lymphocytes are not essential for inducing the tubular changes seen in early diabetic renal injury, thus arguing against lymphocyte interactions with tubules as a mechanism that promotes albuminuria in diabetes.

Rag1 knockout also had no impact on the development of glomerular and interstitial matrix accumulation in diabetic mice. This observation, in conjunction with a lack of lymphocyte effect on tubular injury, suggests that lymphocytes have no significant role in the progression of tubulointerstitial damage in diabetic kidneys. The development of tubulointerstitial fibrosis is considered to be a strong predictor of the decline in renal function in diabetic nephropathy [31]. Therefore, it was not surprising that both wild-type and $\mathrm{Ragl}^{-/}$diabetic mice showed similar increases in interstitial fibrotic responses (myofibroblast accumulation, collagen IV deposition and gene expression of Fn1 and Pai-1) and a similar decline in creatinine clearance.

In conclusion, our study has shown that lymphocytes play a role in the progression of albuminuria, but do not promote renal hypertrophy, increased matrix deposition, tubulointerstitial damage or the decline in renal function in a mouse model of early type 1 diabetic renal injury. Previous evidence has demonstrated that inflammation is critical for the development of diabetic nephropathy. However, our current study suggests that this inflammatory process is primarily due to an innate immune response, which is induced by diabetes and dominated by macrophage-mediated effects. In comparison, adaptive immunity appears to play a more limited role, which includes promotion of glomerular macrophage activation, podocyte injury and albuminuria, in the early development of diabetic renal injury. These results do not preclude a possible role for lymphocytes in the later development of diabetic nephropathy. We expect these findings to be helpful in the development of novel therapies aimed at specifically targeting diabetic renal inflammation.

Acknowledgements We thank P. Frost and E. Ozols for their technical assistance. This study was funded by grants from the National Health and Research Council of Australia, and by Kidney Health Australia.

Duality of interest The authors declare that there is no duality of interest associated with this manuscript.

\section{References}

1. Nguyen D, Ping F, Mu W, Hill P, Atkins RC, Chadban SJ (2006) Macrophage accumulation in human progressive diabetic nephropathy. Nephrology (Carlton) 11:226-231
2. Tesch GH (2007) Role of macrophages in complications of type 2 diabetes. Clin Exp Pharmacol Physiol 34:1016-1019

3. Rabb H, Daniels F, O'Donnell M et al (2000) Pathophysiological role of $\mathrm{T}$ lymphocytes in renal ischemia-reperfusion injury in mice. Am J Physiol Ren Physiol 279:F525-F531

4. Wang Y, Wang YP, Tay YC, Harris DC (2001) Role of CD8(+) cells in the progression of murine adriamycin nephropathy. Kidney Int 59:941-949

5. Nicoloff G, Baydanoff S, Petrova C, Christova P (2002) Antibodies to advanced glycation end products in children with diabetes mellitus. Vascul Pharmacol 39:39-45

6. Atchley DH, Lopes-Virella MF, Zheng D, Kenny D, Virella G (2002) Oxidized LDL-anti-oxidized LDL immune complexes and diabetic nephropathy. Diabetologia 45:1562-1571

7. Nicoloff G, Blazhev A, Petrova C, Christova P (2004) Circulating immune complexes among diabetic children. Clin Dev Immunol $11: 61-66$

8. Bending JJ, Lobo-Yeo A, Vergani D, Viberti GC (1988) Proteinuria and activated T-lymphocytes in diabetic nephropathy. Diabetes 37:507-511

9. Moriya R, Manivel JC, Mauer M (2004) Juxtaglomerular apparatus $\mathrm{T}$ cell infiltration affects glomerular structure in type 1 diabetic patients. Diabetologia 47:82-88

10. Mensah-Brown EP, Obineche EN, Galadari S et al (2005) Streptozotocin-induced diabetic nephropathy in rats: the role of inflammatory cytokines. Cytokine 31:180-190

11. Chow F, Ozols E, Nikolic-Paterson DJ, Atkins RC, Tesch GH (2004) Macrophages in mouse type 2 diabetic nephropathy: correlation with diabetic state and progressive renal injury. Kidney Int 65:116-128

12. Chow FY, Nikolic-Paterson DJ, Ozols E, Atkins RC, Rollin BJ, Tesch GH (2006) Monocyte chemoattractant protein-1 promotes the development of diabetic renal injury in streptozotocin-treated mice. Kidney Int 69:73-80

13. Thiele GM, McDonald TL (1989) Assessment of the role of the immunoglobulin isotypes in the development of diabetic nephropathy in untreated streptozotocin-induced diabetic rats. Diabetes Res $12: 15-24$

14. Xiao X, Ma B, Dong B et al (2009) Cellular and humoral immune responses in the early stages of diabetic nephropathy in NOD mice. J Autoimmun 32:85-93

15. Fujita T, Ohi H, Komatsu K, Endo M, Ohsawa I, Kanmatsuse K (1999) Complement activation accelerates glomerular injury in diabetic rats. Nephron 81:208-214

16. Imani F, Horii Y, Suthanthiran M et al (1993) Advanced glycosylation endproduct-specific receptors on human and rat Tlymphocytes mediate synthesis of interferon gamma: role in tissue remodeling. J Exp Med 178:2165-2172

17. Wen Y, Gu J, Li SL, Reddy MA, Natarajan R, Nadler JL (2006) Elevated glucose and diabetes promote interleukin-12 cytokine gene expression in mouse macrophages. Endocrinology 147: 2518-2525

18. Mombaerts P, Iacomini J, Johnson RS, Herrup K, Tonegawa S, Papaioannou VE (1992) RAG-1-deficient mice have no mature B and T lymphocytes. Cell 68:869-877

19. Burne-Taney MJ, Yokota-Ikeda N, Rabb H (2005) Effects of combined T- and B cell deficiency on murine ischemia reperfusion injury. Am J Transplant 5:1186-1193

20. Rangan GK, Tesch GH (2007) Quantification of renal pathology by image analysis. Nephrology (Carlton) 12:553-558

21. Tesch GH, Allen TJ (2007) Rodent models of streptozotocininduced diabetic nephropathy. Nephrology (Carlton) 12:261266

22. Tay YC, Wang Y, Kairaitis L, Rangan GK, Zhang C, Harris DC (2005) Can murine diabetic nephropathy be separated from superimposed acute renal failure? Kidney Int 68:391-398 
23. Satriano JA, Hora K, Shan Z, Stanley ER, Mori T, Schlondorff D (1993) Regulation of monocyte chemoattractant protein-1 and macrophage colony-stimulating factor-1 by IFN-gamma, tumor necrosis factor-alpha, IgG aggregates, and cAMP in mouse mesangial cells. J Immunol 150:1971-1978

24. Bergtold A, Gavhane A, D'Agati V, Madaio M, Clynes R (2006) FcR-bearing myeloid cells are responsible for triggering murine lupus nephritis. J Immunol 177:7287-7295

25. Ding A, Wright SD, Nathan C (1987) Activation of mouse peritoneal macrophages by monoclonal antibodies to Mac-1 (complement receptor type 3). J Exp Med 165:733-749

26. Di Mario U, Borsey DQ, Contreas G, Prowse CV, Clarke BF, Andreani D (1986) The relationship of soluble immune complexes, insulin antibodies and insulin-anti-insulin complexes to platelet and coagulation factors in type 1 diabetic patients with and without proliferative retinopathy. Clin Exp Immunol 65:57-65
27. Aziz S, Cohen AH, Winer RL, Llach F, Massry SG (1979) Diabetes mellitus with immune complex glomerulonephritis. Nephron 23:32-37

28. Sabnis SG, Antonovych TT (1983) Diabetic nephropathy with superimposed immune complex glomerulonephritis. South Med J 76:456-461

29. Thomson SC, Vallon V, Blantz RC (2004) Kidney function in early diabetes: the tubular hypothesis of glomerular filtration. Am J Physiol Ren Physiol 286:F8-F15

30. Slattery C, Lee A, Zhang Y et al (2008) In vivo visualization of albumin degradation in the proximal tubule. Kidney Int 74:1480 1486

31. Taft JL, Nolan CJ, Yeung SP, Hewitson TD, Martin FI (1994) Clinical and histological correlations of decline in renal function in diabetic patients with proteinuria. Diabetes 43:10461051 